\title{
A Double-Layer Combination Algorithm for Real-Time Information-Sharing Network Design Problem
}

\author{
Qi Sun $\left(\mathbb{D},{ }^{1}\right.$ Liwen Jiang $(\mathbb{D})^{2}$ and Haitao $\mathrm{Xu} \mathbb{D}^{3}$ \\ ${ }^{1}$ Antai College of Economics \& Management, Shanghai Jiao Tong University, Shanghai, China \\ ${ }^{2}$ College of Economics \& Management, Shandong University of Science and Technology, Qingdao, China \\ ${ }^{3}$ Department of Electrical Engineering and Computer Science, Cleveland State University, Cleveland, USA
}

Correspondence should be addressed to Liwen Jiang; jiangliwen@sdust.edu.cn

Received 2 June 2020; Revised 25 January 2021; Accepted 15 February 2021; Published 28 February 2021

Academic Editor: Daniela Paolotti

Copyright (c) 2021 Qi Sun et al. This is an open access article distributed under the Creative Commons Attribution License, which permits unrestricted use, distribution, and reproduction in any medium, provided the original work is properly cited.

\begin{abstract}
The accumulation of real-time data has attracted the attention of various industries because valuable information can be extracted from the effective model and method design. This paper designs a low-carbon model and focuses on the real-time information-sharing network in order to get sustainable strategies promptly and exactly. The design problem is concerned with determining optimal integration strategies on a series of multilocation, multipath, and multiwarehouse freight provided by an information-sharing network to find an effective balance between the total costs and carbon emission. Firstly, the biobjective information-sharing network model is established to describe real-time problem with total cost and carbon emission factor. Secondly, a double-layer bacterial foraging algorithm is divided into inner and outer layers to solve the model, in which the inner section solves the transportation and inventory problems, and the outer section solves the supplier location problem. The double-layer bacterial foraging algorithm realizes the optimization of multisource e-commerce information-sharing model through nesting inside and outside layers. Finally, double-layer bacterial foraging algorithm can be confirmed to get the global optimal solution rapidly based on test data and the e-business case study of Jingdong, China.
\end{abstract}

\section{Introduction}

Energy conservation and emission reduction have become a common concern of the public on environmental issues [1-4]. At present, the global transportation industry accounts for more than $30 \%$ of total carbon dioxide emissions [5]. The logistics information platform can play a major role in the construction of a sustainable, low-carbon economy in the age of big data [6]. Through the layout optimization of the locations of carbon emission node, path plans, and inventory management, it can improve the energy efficiency of transportation, strengthen the useful structure of transportation, and optimize the development mode of logistics system to achieve the low-carbon and sustainable development [7]. The rise of green e-commerce companies will not only increase the efficiency of business activities, promote commercial circulation, and reduce transaction costs but also will upgrade to the development of low-carbon industry chains [8]. The
Jingdong (JD) global online shopping site recently released the "Green Eco-Environmental Strategy Statement" in Beijing and was China's first environmental strategy declaration issued by e-commerce companies. The declaration may also promote JD suppliers and 180 million registered users to implement low-carbon environmental protection concepts. While fulfilling the social responsibilities, the e-commerce companies advocate green and low-carbon business methods and eco-friendly development in China. Not only can they ensure the healthy and sustainable development of enterprises but they can also drive system optimization and many related industries. The integration will lead the consumers to form a low-carbon and environmentally friendly consumption lifestyle.

According to the Chinese e-commerce market Data Monitoring Report in 2013, the transaction volume of the Chinese e-commerce market reached $\$ 1.7$ trillion, a year-onyear increase of $29.9 \%$ [9]. At the same time, it has promoted 
more low-carbon commodity trading behavior. For one thing, people complete the series of processes for merchandise purchase, payment, and delivery through the Internet, which greatly cuts the cost of transportation, settlement vouchers, and so on. For another thing, the reduction of energy consumption in storefronts, the significant compression of storage space, and the corresponding shortening of a transaction process have reduced carbon dioxide emissions. In addition, according to the "Environmental Impact Report for E-Commerce" of the China Center for Circular Economy and Environmental Assessment and Prediction Research, Chinese Academy of Social Sciences, taking 2009 as an example, China's online retail energy consumption is equivalent to a reduction of energy consumption of 63 tons of coal per billion dollars in sales [10]. Based on the estimate of the abovementioned data, the total amount of energy saved in China's e-commerce transactions was equivalent to 7.27 million tons of standard coal and China's online retail sales exceeded thirty million dollars in 2013. Since the 1990s, with the continuous innovation and development of Internet technology, the Internet application has penetrated continuously into various fields, and then the number of companies and individuals has rapidly increased to join the Internet for online deal [11, 12]. However, e-commerce burdens the logistics system directly and increases the energy consumption indirectly as online shopping becomes convenient [13]. Therefore, e-commerce companies should actively use intelligent transportation systems, cloud computing, warehousing optimization systems, green supply chains, new energy vehicles, and other scientific and technological ways and continue to improve the healthy development of low-carbon industry [14].

Compared with traditional trading methods, e-commerce is more suitable for the development of low-carbon economy. For example, with the click of a mouse, consumers can easily complete a series of processes from commodity purchase to payment and collection, which greatly reduces the consumption of transportation, logistics, storage, and other energy resources related to transaction and effectively reduces carbon emissions and saves time. By August 2019, Alipay Ant Forest has attracted over 500 million users, resulting in 122 million trees planted in arid areas in China and the avoidance of 7.9 million tons of carbon emissions. In the process of building a low-carbon society, the positive role of e-commerce has been fully demonstrated. The development of e-commerce is beneficial for enterprises to realize the optimal allocation of resources in a wider range and improve the value of supply chain. Moreover, because of its environmental characteristics of low carbon, low energy consumption, and low emission, e-commerce will further change human life and become an important and effective way to develop low-carbon economy. E-commerce business digitizes traditional business processes and reduces the waste of resources in many physical logistics. Amazon found that smaller basket sizes can help reduce carbon emissions from online grocery delivery by an average of $43 \%$. Smaller basket sizes generate even greater carbon savings. Shopping in-person process emits approximately $0.2 \mathrm{~kg}$ more carbon dioxide than conducting the entire journey digitally. Digital information-sharing platform system can greatly reduce labor, material resources, and costs. E-commerce integrates science and technology to reflect the scientific and comprehensive understanding of nature and human society and makes sustainable economic development possible. On the other hand, e-commerce has broken through the limitations of time and space, allowing transactions to be conducted anytime and anywhere, thus greatly improving efficiency. The real-time information-sharing network has changed the traditional concept of space and prompted the emergence of virtual space and society, different from the actual geographical space. Individuals, companies, and organizations in any corner of the world can be closely linked through the Internet platform to establish virtual communities and virtual companies to achieve information sharing, resource sharing, and intelligence sharing. The openness and global features of e-commerce have created more trade opportunities for companies. E-commerce information-sharing platform has redefined the customary circulation model, cut the intermediate links, and made direct transactions between producers and consumers, and thus it will change the way of the entire social economy to a certain extent.

With the increasingly fierce market competition, the continuous improvement in terminal customers' personalized and diversified requirements has led decision makers to pay more and more attention to coordinating relationships to node members of the network. The main contents of the real-time information-sharing network include the following five aspects: (1) Sharing Inventory. The inventory-sharing platform is an effective guarantee of realizing the real-time performance of the network. (2) Sales Data Sharing. Platform members can analyze sales trends, customer preferences, and customer distribution through sales data to determine inventory levels, shelf layouts, and new product development, and so on. (3) The Order Status. Knowing the status of orders in a timely manner can improve decision-making efficiency. (4) RealTime Feedback. Through real-time feedback systems, information can be delivered to decision makers as quickly as possible, so that the "bullwhip effect" and inventory levels can be reduced. (5) Production-Distribution Plans. On the one hand, production nodes can improve their own planning levels according to the distribution plans of suppliers. On the other hand, suppliers can provide production nodes with reliable supplies according to requirements planning.

\section{Literature Review}

In recent years, with the increasingly prominent environmental issues, low-carbon optimization model has attracted the attention of some scholars. Carrillo et al. [15] believed that consumers are more inclined to shops through online channels with environmental awareness increasing, so platform decision makers should design and apply the dualchannel marketing model. Chung et al. [16] studied the production selection problem of manufacturing enterprises under the pollution tax. When the emission reduction efforts are increased, enterprises prefer to purchase materials rather than processing them themselves, so as to reduce the 
pollution cost. Caro et al. [17] focused on formulating the carbon allocation rules of the supply chain through social planners and the enterprises with high emission reduction costs will voluntarily pay compensation to enterprises with low emission reduction costs to realize the optimal carbon supply chain. Hoen et al. [18] incorporated carbon awareness into business management and changed the traditional transport model. The results showed that transport mode conversion can indeed reduce carbon emissions and rely on carbon emission reduction regulations. Zhao et al. [19] designed risk tolerance to divide the three levels (intolerable, tolerable, and acceptable) of government's tolerance for the carbon emission of enterprises.

Carbon quota is the basis of cap-and-trade mechanism, but it is limited so it is necessary to design and optimize the model to control carbon emissions. Diabat and Simchi-Levi [20] used a mixed-integer programming model to study the problem of two-level multicommodity supply chain network design under carbon-quota constraints. Chaabane et al. [21] studied the sustainable design of a supply chain under emissions trading from the economic, environmental, and social aspects according to the principle of life cycle assessment. Bouchery et al. [22] determined the optimal ordering strategy for companies under the economic, environmental, and social standards through the sustainable order quantity (SOQ) model, and the results show that policies based on carbon quotas are more effective. Giarola et al. [23] designed a mixed-integer linear programming model to study the design and planning of a multilevel bioethanol supply chain under the carbon credit quota trading scheme and found that the model can guide long-term decision-making and investment. Benjaafar et al. [24] combined traditional models with carbon emission issues such as carbon quotas, strategies for vendor production, and inventory operations under trading and concluded that carbon emission parameters can modulate supply chain costs and emissions. Gong and Zhou [25] studied the manufacturer's choice of production technology under the carbon emission trading mechanism and determined the production technology based on the level of carbon emissions and the production quantity.

The real-time information-sharing network design problem is a joint rising operational issue in the new era, which has become a hot and difficult academic research. Liu and Lee [26] decomposed e-commerce sharing information into two subproblems: one is a facility location-allocation problem; the other is a path selection and inventory control problem. A heuristic algorithm was designed to find the initial solution, and then tabu search was a built-in combination with simulated annealing hybrid algorithm to improve the initial solution. Wang [27] designed a distribution system consisting of a central warehouse, multiple potential suppliers, and multiple retailer warehouses to create a nonlinear mixed-integer programming model and developed the Lagrangian relaxation algorithm. Yao et al. [28] studied the problem of multisource facility location, allocation, and inventory control when there was a need for safety stocks and a certain level of customer service under stochastic demand conditions.

There is relatively little research on the integration of environmental issues with location-path-inventory problem, most of which only look at low-carbon operations at a certain point. Ballota and Fontane [29] studied how to reduce overall carbon emissions through inventory sharing, and at least $25 \%$ of $\mathrm{CO}_{2}$ emissions will be saved when the warehouse is centralized. Harris et al. [30] examined the relationship between carbon emissions from warehouse electricity, transportation, and total cost and the results showed that the optimal solution of cost may not be consistent with the carbon emission optimal solution. Mallidis et al. [31] conducted a study on carbon emissions from transport mode selection and warehouse sharing and found that thirdparty logistics should use sharing warehouses to improve the environmental performance. Pan et al. [32] discussed carbon emission from transport modes and pathways and made a combination of road and rail transport to reduce emissions by up to $52 \%$. Demir et al. [33] studied the carbon emissions from vehicle transportation using a biobjective model and determined the best distribution route based on the minimum fuel consumption and the shortest travel time.

To sum up, the current research on sharing network design problem with environmental constraints mainly has the following deficiencies. Firstly, due to the limitation of hardware facilities, real-time performance is not considered for network optimization. Existing literature focused on optimizing-related parameters of carbon emission (Caro et al. [17]; Hoen et al. [18]; Zhao et al. [19]; Diabat and Simchi-Levi [20]). Secondly, the degree of data mining and the efficiency of information utilization are insufficient. Some scholars have paid attention to the data sharing of location, path, and warehouse but the method design is not enough (Liu and Lee [26]; Ballot and Fontane [29]; Mallidis et al. [31]). Thirdly, the study on the problem of locationpath-inventory with environment and multifacility sources is also considered rarely. Algorithm research on low-carbon optimal integration of multisource facilities needs to be strengthened and enriched further (Wang [27]; Yao et al. [28]; Harris et al. [30]). In view of this, the paper explicitly proposes the real-time information-sharing location-pathinventory integration network optimization model with low-carbon conditions and put forward double-layer bacterial foraging algorithm.

\section{The Model of Real-Time Information-Sharing Network Design Problem}

The bottom layer of the information platform is data and information flow, so it needs a robust mathematical model to describe. This model design includes problem description and hypothesis, the real-time carbon emission model for e-commerce network structure with sharing information, and the real-time information-sharing model. 
3.1. Problem Description and Hypothesis. The real-time information-sharing network design structure is composed of multiple production nodes (e.g., producer and manufacturer), multiple supply nodes (e.g., JD.com, Amazon, eBay, and other suppliers or retailers) and multiple consumer nodes as showed in Figure 1. The network design in this paper considers the beginning, circulation, and terminal. Therefore, the supply node of circulation link is defined from the perspective of topology, which plays a connecting role in the network and is the main executor of network decision.

Multiple production nodes $m(m=1,2, \ldots, M)$ are distributed to potential supply nodes $n(n=1,2, \ldots, N)$ within capacity constraints. The material and information flow processes include the production nodes transportation, location selection of supply nodes, and inventory issues. Then, supply nodes determine distribution path solutions to complete orders processing and purchasing services for the multiple consumer nodes marked as $r(r=1,2, \ldots, R)$. The carbon emissions of the network model mainly come from the transportation among production nodes and consumer nodes and warehouse operation. Information-sharing multifacility integration network model is established with low-carbon constraints to get the best operational decision by real-time platform.

Real-time is an important feature of the parameters carried by the Internet to describe the recent and ongoing state changes through data terminal, manual operation, block chain, etc. According to a report by Deloitte, $80 \%$ of enterprises believe that digital supply chain will be dominant in the next five years, and $16 \%$ of enterprises think that digital supply chain is already dominant. Therefore, each node has a time dependent variable in the mathematical model and the research model of this paper is based on the following assumptions:

(1) The production node $m(t)$ contains time point $t$ and connects with one or more supply nodes.

(2) The supply node $n(t)$ contains time point $t$ and determines the optimal selection based on the distance $\operatorname{dis}_{m(t) n(t)}$ and the fixed cost of supply nodes.

(3) Each consumer node $r(t)$ contains time point $t$ and demands of consumer obey normal distribution independently.

(4) The node member can abide by the carbon emission regulations consciously. The upstream and downstream operations of the network are coordinated under a defined carbon quota $C_{\max }(t)$, regardless of the carbon quota remaining, but the excess must be paid to the government for carbon punishment.

(5) Low-carbon sustainability factor is noted by $\varepsilon(t)$ to quantify the intensity of constraint about low carbon in existing studies, for example, studies by Caro et al.

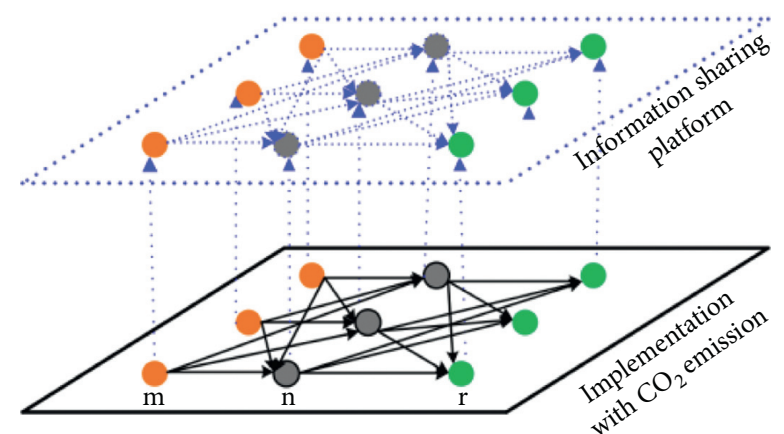

Production node

Supply node

Consumer node $\ldots$. Information flow

$\rightarrow$ Material flow
FIgURE 1: The real-time information-sharing network design structure.

[17], Hoen et al. [18], Zhao et al. [19], and Diabat and Simchi-Levi [20], which means to convert the excess carbon emissions into penalties in the network model.

(6) This paper focuses on network design, considering the circulation of a class of goods, so the market situation of multiple products is not within research scope. The inventory is considered in the range of $T,\{1, \ldots, t, \ldots, T\}$. It will take time to transport products from the manufacturer to the supplier as $\operatorname{dis}_{m(t) n(t)}$. At time point, statistics are conducted for products transportation to the suppliers once per decision cycle $T,\{1, \ldots, t, \ldots, T\}$.

In this study, symbols are shown as follows:

(1) Decision variables:

(i) $x_{m(t) n(t)}$ : the total volume of shipments from production node $m(t)$ to supply node $n(t)$.

(ii) $x_{n(t) r(t)}$ : the total volume of shipments from supply node $n(t)$ to consumer node $r(t)$.

(iii) $y_{n(t)}$ : if the supply node $n(t)$ is available, the value will be 1 , otherwise 0 .

(iv) $Y_{m(t) n(t)}$ : if the supply node $n(t)$ is serviced by the production node $m(t)$, the value will be 1 , otherwise 0 .

(v) $Z_{n r}$ : if the consumer node $r(t)$ is served by the supply node $n(t)$, the value will be 1 , otherwise 0 .

(2) Parameter description

(vi) $M$ : the collection of product production nodes.

(vii) $N$ : the collection of potential supply nodes.

(viii) $R$ : the collection of consumer nodes. 
(ix) $T$ : the time domain of time point $t$.

(x) $g_{n}$ : the fixed costs of potential supply node $n(t)$.

(xi) $w_{m(t) n(t)}$ : the transportation cost from the production node $m(t)$ to the supply node $n(t)$ for unit product.

(xii) $w_{n(t) r(t)}$ : the transportation cost from the supply node $n(t)$ to the consumer node $r(t)$ for unit product.

(xiii) $h_{n(t)}$ : the inventory holding cost of supply node $n(t)$ for unit product.

(xiv) $\alpha$ : the probability of shortage; therefore, $1-\alpha$ represents the corresponding service level.

(xv) $z_{\alpha}$ : the safety stock.

(xvi) $L$ : the lead time.

(xvii) $u_{r(t)}$ : the average demand of the consumer node $r(t)$.

(xviii) $\sigma_{r(t)}$ : the standard deviation of demand for consumer node $r(t)$.

(xix) $\operatorname{dis}_{m(t) n(t)}$ : the distance between production node $m(t)$ and supply node $n(t)$.

(xx) $\operatorname{dis}_{n(t) r(t)}$ : the distance between supply node $n(t)$ and consumer node $r(t)$.

(xxi) $M_{m(t)-\max }$ : the production node $m(t)$ 's maximum production capacity.

(xxii) $N_{n(t)-\max }$ : the supply node $n(t)$ 's maximum storage capacity.

(xxiii) $C_{\max }$ : the maximum of carbon emission in the network model.

(xxiv) $\varepsilon$ : the low-carbon sustainability factor.

(xxv) $c g_{n}$ : the fixed carbon emissions of supply node $n(t)$.

(xxvi) $c i_{n(t)}$ : the carbon emissions from inventory operations of supply node $n(t)$ for unit product.

(xxvii) $c t_{m(t) n(t)}$ : the carbon emissions within unit distance from the production node $m(t)$ to the supply node $n(t)$ for unit product.

(xxviii) $c t_{n(t) r(t)}$ : the carbon emissions from the supply node $n(t)$ to the consumer node $r(t)$ for unit product.

\subsection{The Real-Time Carbon Emission Model for E-Commerce} Network Structure with Sharing Information. Carbon emissions of information-sharing system mainly come from the construction of node facilities in the distribution center of the network, transportation between nodes, and inventory operations. The carbon emissions at each stage are measured and analyzed as follows:

(1) The real-time carbon emissions from the node facility construction:

The carbon emissions from the construction of node facilities in the distribution center of networks are mainly caused by the scale of supply nodes, such as fixed consumption of water, electricity, and energy. The total carbon emissions as CG for all facility construction are linearly related to the number of selected supply nodes. $g_{n}$ is a fixed coefficient and $y_{n(t)}$ changes because the decision will change in different time ranges based on variable information, and then the decision variable $y_{n(t)}$ will affect $C G$ with the change of time update strategy,

$$
C G=\sum_{n=1}^{N} \sum_{t=1}^{T} c g_{n} y_{n(t)},
$$

(2) The real-time carbon emissions during transportation:

The carbon emissions during transportation are influenced by the distance $\operatorname{dis}_{m(t) n(t)}$ between production nodes and supply nodes, the amount $c t_{m(t) n(t)}$ for carbon emissions per unit distance, the total amount $x_{m(t) n(t)}$ for shipments, and the location of potential supply nodes. Then, the carbon emissions $C T_{m(t) n(t)}$ during transportation can be derived as follows:

$C T_{m(t) n(t)}=\sum_{m=1}^{M} \sum_{n=1}^{N} \sum_{t=1}^{T} c t_{m(t) n(t)} d i s_{m(t) n(t)} x_{m(t) n(t)} Y_{m(t) n(t)}$.

The amount $c t_{m(t) n(t)}$ for carbon emissions per unit distance is affected by various factors such as road conditions and vehicle types. To simplify the calculation, it is considered as a fixed value in this paper. The total carbon emission from the production node $m(t)$ to the supply node $n(t)$ is directly related to the 0 -1 variable $Y_{m(t) n(t)}$. In the same way, the carbon emissions can be obtained from the supply node $n(t)$ to the consumer node $r(t)$,

$C T_{n(t) r(t)}=\sum_{n=1}^{N} \sum_{r=1}^{R} \sum_{t=1}^{T} c t_{n(t) r(t)} d i s_{n(t) r(t)} x_{n(t) r(t)} Z_{n(t) r(t)}$.

$C T_{m(t) n(t)}$ plus $C T_{n r}$ is equal to the total carbon emissions $C T$ for the entire distribution process of the network.

(3) The real-time carbon emissions of inventory operation:

The e-commerce model of this paper is put forward under the background of the digital supply chain (e.g., Emitwise, http://bit.ly/EmitwiseLinkedin, a London-based start-up, has designed a platform to track the company's carbon emissions in real time). It mainly examines the carbon emissions generated by the current inventory and safety inventories held by supply nodes. Each supply node can distribute for multiple consumer nodes, so the current inventory level of supply nodes is influenced by demand from the consumer node, and the level of safety stock is related to the lead time $L$ for orders. The demand 
variable of each consumer node is normal distribution (as the discrete variable point, the consumer demand can be counted in the sharing information system, such as Poisson distribution, exponential distribution, and normal distribution), and the carbon emission of supply node is noted by CI in network database,

$$
C I=\sum_{t=1}^{T} \sum_{n=1}^{N} c i_{n(t)}\left(\sum_{r=1}^{R} \frac{x_{n(t) r(t)}}{\sum_{n=1}^{N} x_{n(t) r(t)}} u_{r(t)} Z_{n(t) r(t)}+z_{\alpha} \sqrt{\sum_{r=1}^{R} L \frac{x_{n(t) r(t)}}{\sum_{n=1}^{N} x_{n(t) r(t)}} \sigma_{r(t)}^{2} Z_{n(t) r(t)}}\right)
$$

The real-time carbon emissions from the selected site, distribution, transportation, and inventory operation are integrated, and then the carbon emission quantity objective function of network structure with e-commerce information sharing is constructed as $f_{1}$,

$$
\begin{aligned}
& f_{1}=\operatorname{Min}(C G+C T+C I)=\operatorname{Min}\left\{\sum_{t=1}^{T} \sum_{n=1}^{N} c g_{n} y_{n(t)}+\sum_{t=1}^{T} \sum_{m=1}^{M} \sum_{n=1}^{N} c t_{m(t) n(t)} d i s_{m(t) n(t)} x_{m(t) n(t)} Y_{m(t) n(t)}\right. \\
& \quad+\sum_{t=1}^{T} \sum_{n=1}^{N} \sum_{r=1}^{R} c t_{n(t) r(t)} d i s_{n(t) r(t)} x_{n(t) r(t)} Z_{n(t) r(t)}+\sum_{t=1}^{T} \sum_{n=1}^{N} c i_{n(t)}\left(\sum_{r=1}^{R} \frac{x_{n(t) r(t)}}{\sum_{n=1}^{N} x_{n(t) r(t)}} u_{r(t)} Z_{n(t) r(t)}+z_{\alpha}\right] \sum_{r=1}^{R} \\
& \text { s.t. } \quad M_{m(t)-\max }-\sum_{t=1}^{T} \sum_{m=1}^{M} \sum_{n=1}^{N} x_{m(t) n(t)} Y_{m(t) n(t)} \geq 0, \\
& N_{n(t)-\max }-\sum_{t=1}^{T} \sum_{m=1}^{M} \sum_{n=1}^{N} x_{m(t) n(t)} Y_{m(t) n(t)} \geq 0, \\
& \sum_{t=1}^{T} \sum_{m=1}^{M} \sum_{n=1}^{N} x_{m(t) n(t)}-\sum_{t=1}^{T} \sum_{r=1}^{R} \sum_{n=1}^{N} x_{r(t) n(t)}=0, \\
& \sum_{t=1}^{T} \sum_{r=1}^{R} \sum_{n=1}^{N} x_{n(t) r(t)} Z_{n(t) r(t)}-u_{r(t)} \geq 0, \\
& Y_{m(t) n(t)}=0,1 \quad m \in M, n \in N, t \in T, \\
& Z_{n(t) r(t)}=0,1 \quad n \in N, r \in R, t \in T, \\
& y_{n(t)}=0,1 \quad n \in N, t \in T .
\end{aligned}
$$$$
\left.+\sum_{t=1}^{T} \sum_{n=1}^{N} \sum_{r=1}^{R} c t_{n(t) r(t)} d i s_{n(t) r(t)} x_{n(t) r(t)} Z_{n(t) r(t)}+\sum_{t=1}^{T} \sum_{n=1}^{N} c i_{n(t)}\left(\sum_{r=1}^{R} \frac{x_{n(t) r(t)}}{\sum_{n=1}^{N} x_{n(t) r(t)}} u_{r(t)} Z_{n(t) r(t)}+z_{\alpha} \sqrt{\sum_{r=1}^{R} L \frac{x_{n(t) r(t)}}{\sum_{n=1}^{N} x_{n r}} \sigma_{r(t)}^{2} Z_{n(t) r(t)}}\right)\right\}
$$

The objective function $f_{1}$ indicates the total carbon emissions that the platform can monitor are the minimum. Condition formula (5) means that production nodes produce goods which cannot exceed the production capacity constraints. Condition (5) indicates the storage capacity constraint to intermediate node. Condition (5) describes the quantity of production and the balance between supply and demand. Condition (5) guarantees that the inventory level of supply node is positive. Condition (5) determines whether the supply node $n(t)$ is served by the production node $m(t)$. Condition (5) represents whether the consumer node $r(t)$ is served by the supply node $n(t)$. In addition, condition (5) means whether the supply node $n(t)$ is selected.

Manufacturers and suppliers are members of the shared information network and both may belong to different industrial fields, forming a digital supply chain through information-sharing network. This kind of carbon emission by consumer shopping behavior is ineffective for everyone, but as a market in a field, the total carbon emission is huge. Therefore, in the research, the decision makers of every enterprise should consider the carbon emission limit for a conceivable and meaningful research hypothesis and also 
provide suggestions for the government. The total carbon emission is set as $T T$ and the carbon quota of the entire network as $C_{\max }$. Science-based targets initiative (SBTI) publicizes the scientific carbon target verification results of Jingdong Logistics (JDL) on the official website. Under the guidance of the committee, the carbon reduction goal of JDL in 2030 is to reduce the total carbon emission by $50 \%$ by 2030 compared with that in 2019. It means that JDL has become the first logistics enterprise to complete the carbon target in China. When $T T-C_{\max }>0$, if the whole network exceeds the emission limit, it will need to pay the government for the carbon punishment cost. When $\varepsilon=\theta$, the lowcarbon sustainability factor $\varepsilon$ is set to convert excess carbon emissions into part of the costs of the whole network through the government and public awareness. Since the remainder of the carbon quota is not considered, when $T T-C_{\max }<0, \varepsilon=0$. The calculation of transport carbon emissions is based on the statistical time and vehicle model (for the same logistics company, the vehicle model is basically unified). After the carbon quota is determined, the actual distribution process needs to be measured. Transportation model is identical but the condition of vehicles and roads among nodes is not the same. Aviation fuel emissions can be accurately estimated by time, speed, and transportation of fuel. Carbon emission of the vehicle (such as a truck) should fully consider the characteristics of road surface and the complexity of ground traffic.

As shown in Figure 2 [34], the slope of the road is $\alpha_{i j}$, and the ground resistance is $F_{r} . G=m g$ is the total gravity of the vehicle. $G=m g . F_{N}$ represents the supporting force of the ground. The speed of the vehicle is denoted as $v_{i j}$. Distribution distance from $i$ to $j$ is $L_{i j}$. According to Newton's law, $\sum F_{\mathrm{y}}=F_{m}-F_{r}-G \sin \alpha_{i j}=m a_{y}$ and $\sum F_{x}=F_{N}-G \cos \alpha_{i j}=m a_{x}$. The engine of a vehicle needs to do work of $W_{i j}=F_{m} L_{i j}$. Total carbon emission is $e_{1} \times e_{2} \times \sum W_{i j}$, where $e_{1}$ is the fuel conversion factor (gal/ Joule), $\sum W_{i j}$ is the effective fuel capacity, and $e_{2}$ is carbon emissions per unit of fuel ( $\mathrm{kg} /$ gallon).

3.3. The Real-Time Information-Sharing Model. The cost of network platform operation under e-commerce information sharing consists of the fixed cost and variable cost. According to the quantity analysis of carbon emission process, the cost composition of siting-path-inventory can be obtained by three parts.

(1) Construction cost of supply node for site selection:

$$
G=\sum_{n=1}^{N} g_{n} y_{n(t)}
$$

(2) Delivery and transportation costs:

The transportation cost includes the cost from the production node to the supply node and the fee from the supply node to the consumer node. The expression of the transportation cost at time point $t$ is noted as Tra,

$$
\begin{aligned}
\operatorname{Tra}= & \sum_{m=1}^{M} \sum_{n=1}^{N} w_{m(t) n(t)} d i s_{m(t) n(t)} x_{m(t) n(t)} Y_{m(t) n(t)} \\
& +\sum_{n=1}^{N} \sum_{r=1}^{R} w_{n(t) r(t)} \operatorname{dis}_{n(t) r(t)} x_{n(t) r(t)} Z_{n(t) r(t)} .
\end{aligned}
$$

(3) Inventory operation costs:

Considering the average expected inventory, holding costs, and safety stock, the total inventory costs at time point $t$ are as follows:

$$
\mathrm{IN}=\sum_{n=1}^{N} h_{n(t)}\left(\sum_{r=1}^{R} \frac{x_{n(t) r(t)}}{\sum_{n=1}^{N} x_{n(t) r(t)}} u_{r} Z_{n(t) r(t)}+z_{\alpha} \sqrt{\sum_{r=1}^{R} L \frac{x_{n(t) r(t)}}{\sum_{n=1}^{N} x_{n(t) r(t)}} \sigma_{r(t)}^{2} Z_{n(t) r(t)}}\right)
$$

The abovementioned construction costs of the supply node, distribution transportation costs between nodes, and inventory operating costs of the network node are summed to build a multisource real-time information-sharing cost objective function $f_{2}=\operatorname{Min}(G+\operatorname{Tr} a+I N)$ with constraint conditions (5). Therefore, the objective function $f_{1}$ of minimum carbon emissions and $f_{2}$ of minimum multisource e-commerce information-sharing cost make up a dual-target problem together, which are integrated with the environmental constraint, and then a multisource real-time information-sharing model with the low-carbon sustainability factor is constructed as follows: 


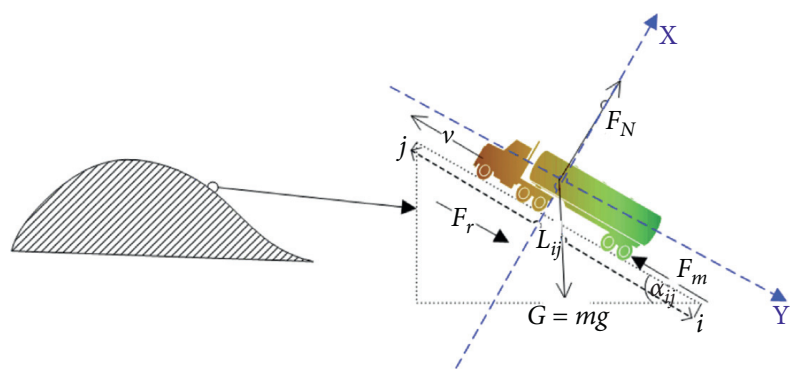

FIgURE 2: The mechanical decomposition of vehicle for carbon emission calculations.

$$
\begin{aligned}
& f=\operatorname{Min}\left\{(G+\operatorname{Tr} a+I N)+\varepsilon\left((C G+C T+C I)-C_{\max }\right)\right\} \\
& =\operatorname{Min}\left\{\sum_{n=1}^{N} g_{n(t)} y_{n(t)}+\sum_{m=1}^{M} \sum_{n=1}^{N} w_{m(t) n(t)} \operatorname{dis}_{m(t) n(t)} x_{m(t) n(t)} Y_{m(t) n(t)}+\sum_{n=1}^{N} \sum_{r=1}^{R} w_{n r} \operatorname{dis}_{n r} x_{n r} Z_{n r}\right. \\
& +\sum_{n=1}^{N} h_{n(t)}\left(\sum_{r=1}^{R} \frac{x_{n r}}{\sum_{n=1}^{N} x_{n(t) r(t)}} u_{r(t)} Z_{n(t) r(t)}+z_{\alpha} \sqrt{\sum_{r=1}^{R} L \frac{x_{n(t) r(t)}}{\sum_{n=1}^{N} x_{n(t) r(t)}} \sigma_{r(t)}^{2} Z_{n(t) r(t)}}\right) \\
& +\varepsilon\left(\left(\sum_{n=1}^{N} c g_{n} y_{n(t)}+\sum_{n=1}^{N} c i_{n(t)}\left(\sum_{r=1}^{R} \frac{x_{n(t) r(t)}}{\sum_{n=1}^{N} x_{n(t) r(t)}} u_{r(t)} Z_{n(t) r(t)}+z_{\alpha} \sqrt{\sum_{r=1}^{R} L \frac{x_{n(t) r(t)}}{\sum_{n=1}^{N} x_{n(t) r(t)}} \sigma_{r(t)}^{2} Z_{n(t) r(t)}}\right)\right.\right. \\
& \left.\left.\left.+\sum_{m=1}^{M} \sum_{n=1}^{N} c t_{m(t) n(t)} d i s_{m(t) n(t)} x_{m(t) n(t)} Y_{m(t) n(t)}+\sum_{n=1}^{N} \sum_{r=1}^{R} c t_{n(t) r(t)} \operatorname{dis}_{n(t) r(t)} x_{n(t) r(t)} Z_{n(t) r(t)}\right)-C_{\max }\right)\right\}
\end{aligned}
$$

The constraint of objective function (9) is the same as (5), but it is especially necessary to add the environmental constraints $\varepsilon=\left\{\begin{array}{l}0, T T \leq C_{\max } \\ \theta, T T>C_{\max }\end{array}\right.$, indicating the relationship between public environmental awareness and the carbon punishment of the network structure.

\section{Double-Layer Bacterial Foraging Algorithm and Computational Results}

In BFA, by implementing its reproduction strategy, half of the bacteria are discarded, and each of the remaining ones is simply split into two identical individuals. This reduces the diversity of the population. The real-time informationsharing model is constructed involving the issues of site selection, route selection, inventory operation, and environmental awareness. The double-layer bacterial foraging algorithm (DBFA) is designed and improved based on the particle swarm algorithm (PSO). The fast convergence rate is favorable but easily trapped in local optimum. The bacterial foraging algorithm can find the global optimal solution rapidly. Traditional BFA has the characteristics of slow convergence (Gao et al. [35] and Wang and Lu [36]), so the design method is divided into the inner layer and outer layer to solve the model. Among them, the inner layer of DBFA solves the transportation and inventory problems for supply node, and the outer layer algorithm solves the problem of multiple supply nodes to realize the optimization of realtime information-sharing model through nesting inside and outside layers.

4.1. The Design Ideas of Double-Layer Combination Algorithm. DBFA is a global optimization algorithm based on the group movement behavior of bird flock. The design idea of the algorithm is that each flying particle corresponds to the fitness value determined by the objective function. Through the evaluation of the particle adaptation value, the best position of the particle is found. The algorithm constantly updates its own optimal position, including population optimal position, the particle position, and finally reaches the optimal solution of the entire particle swarm. The flow chart of the outer and inner layers of the DBFA is shown in Figures 3 and 4, respectively.

In the design of the algorithm, it is considered that the speed of time updating data is very fast, but the attribute of decisionmaking problem is different. The decision-making change of location problem is slow and long-term, while the inventory and transportation problem is changeable and short-term, so DBFA is divided into inner and outer layers to solve the model, in which the inner section solves the transportation and inventory problems in Figure 3, and the outer section solves the supplier location problem in Figure 4. 


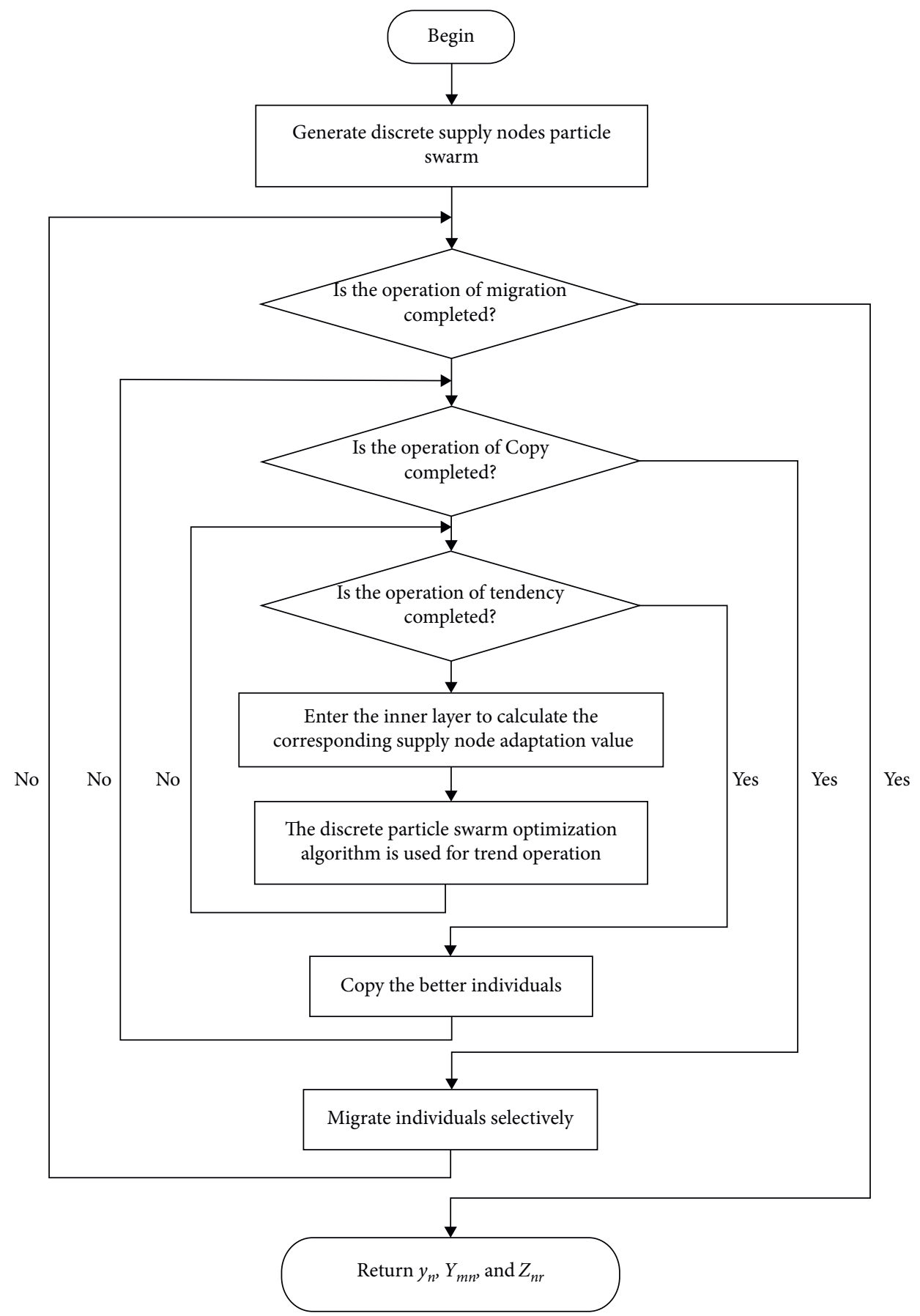

Figure 3: The outer layer of double-layer combination algorithm.

DBFA achieves learning and renewal of bacterial populations through particle swarm taxis and uses the duplication process to complete population renewal. Then, the migration process allows new bacteria to be produced in the collection of bacteria. The specific mathematical description is as follows: 


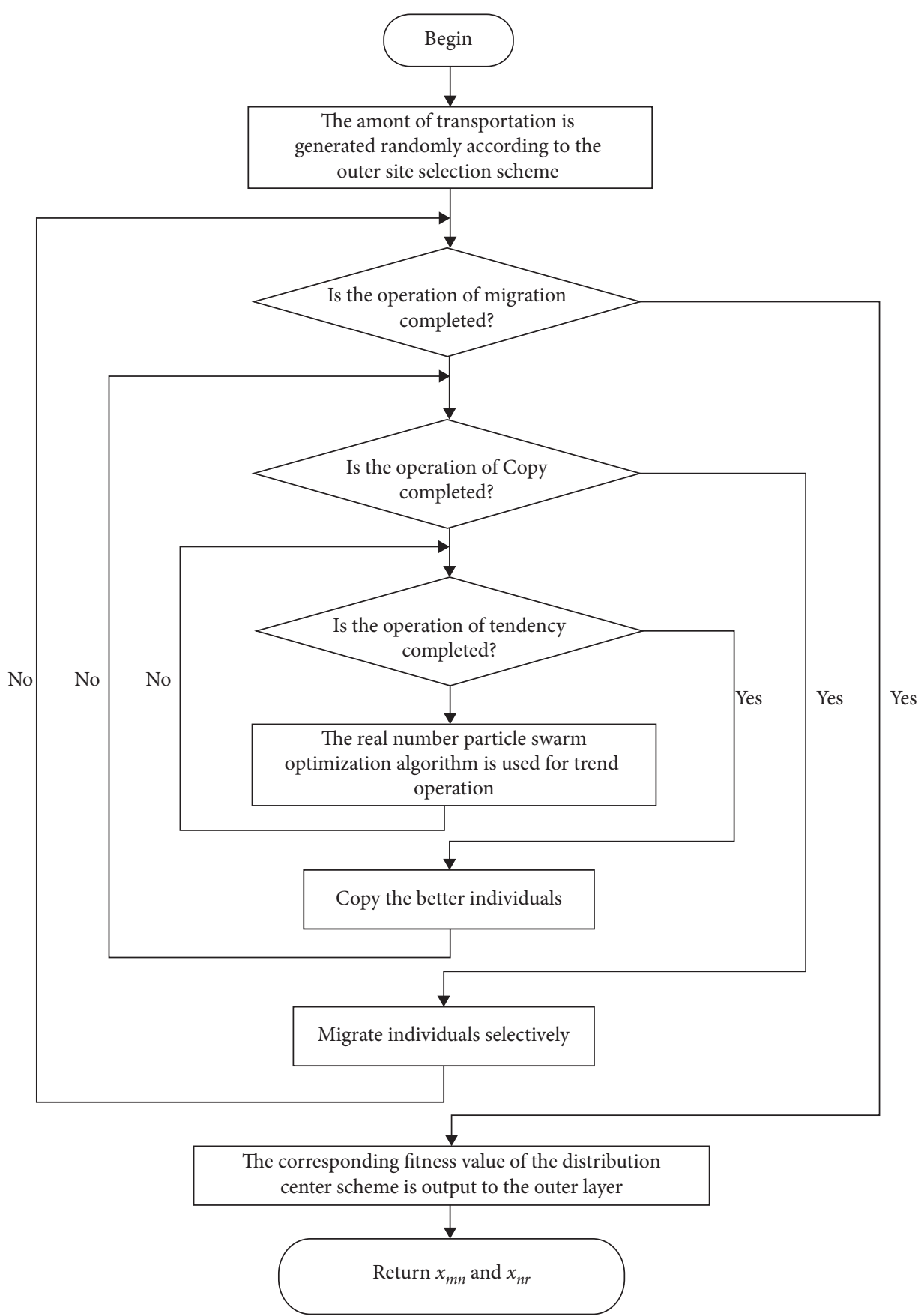

FIgURE 4: The inner layer of double-layer combination algorithm.

(1) Particle population chemotaxis:

Chemotaxis is the most important step for bacteria to achieve optimal foraging. It first defines the unit step size of bacteria moving in any direction as turnover. When bacteria complete a turnover, if the fitness value is improved, it will continue to move along the same direction until the fitness value no longer improves or reaches the predetermined number of moving steps. This process is defined as swimming. Chemotactic behavior of bacterial foraging algorithm can be described as (10).
Let $P(i, j, k, l)$ denote the position of the individual $i$, where $j$ represents the trend cycle of generation $j ; k$ indicates the copy cycle of generation $k$; and $l$ means the migration of generation $l$. In formula (10), $\Phi(i)=$ $\left((\Delta(i)) /\left(\sqrt{\Delta^{T}(i) \Delta(i)}\right)\right)$ indicates the direction where the bacteria have been adjusted. $\Delta(i)$ is the generated random vector $C(i)$ which represents the unit step size to swim in the selected direction. The essence of chemotaxis is that bacteria search the neighborhood of feasible solution in the solution space and 
determine whether to continue swimming in the direction or adjust the direction again by fitness function. Chemotactic operators ensure that the bacterial monomer can always find the optimal value in its neighborhood:

$$
\begin{aligned}
P(i, j+1, k, l) & =P(i, j, k, l)+C(i) \Phi(i), \\
v_{i d}(t+1) & =w v v_{i d}(t)+c_{1} r_{1}\left(P_{b}(t)-x_{i d}(t)\right)+c_{2} r_{2}\left(P_{g}(t)-x_{i d}(t)\right) .
\end{aligned}
$$

In a d-dimensional target search space, $N$ particles form a group, and the position of the $i$ th particle is represented as a d-dimensional vector $X_{i}=\left(x_{i 1}, x_{i 2}, \ldots, x_{i d}, \ldots x_{i D}\right), \quad i=1,2, \cdots, N$. The position of each particle is a potential solution. The velocity of the $i$-th particle is also a d-dimensional vector in $V_{i}=\left(v_{i 1}, v_{i 2}, \ldots, v_{i d}, \ldots v_{i D}\right)$. A group of random particles are initialized, and then the optimal solution is found by iteration. In each iteration, particles update their positions by tracking two extreme values. The first is the optimal solution found by the particle itself, which is called individual extremum as $P_{b}$. The other extreme value is the optimal solution of the whole population, which is the global extremum $P_{g}$. Then, the velocity and position of particles can be updated by the following formula (10).

(2) Copying process:
If the size of the bacterial population is $M$, the number of bacteria eliminated in the replication process will be $M_{r}=(M / 2)$. The bacteria are sorted according to the size of the fitness value, and the front $M_{r}$ bacteria with a higher fitness value are removed. After the replication, $M_{r}$ bacteria will be filled consistent with the previous population size.

(3) Migration process:

The probability of bacterial migration is noted as $P_{r}$. If a certain bacterial individual is able to adapt to the conditions for migration, the bacterial individual will be removed and a new bacterial individual will be regenerated, which is equivalent to migrate the original bacteria to a new location. Based on this principle, in order to relax the target constraint condition, a fitness function of the model is constructed, and the constraint condition of the target is converted into a penalty function. The constraint conditions (5) are converted as follows:

$$
\begin{aligned}
& a_{m}=M_{m-\max }-\sum_{n \in N} x_{m n} Y_{m n}, \quad(m=1,2, \ldots, M), \\
& b_{n}=N_{n-\max }-\sum_{m \in M} x_{m n} Y_{m n}, \quad(n=1,2, \ldots, N), \\
& c_{r}=\sum_{n \in N} x_{n r} Z_{n r}-u_{r} \geq 0, \quad(r=1,2, \ldots, R), d_{n}=\left|\sum_{m \in M} x_{m n}-\sum_{r \in R} x_{n r}\right|, \quad(n=1,2, \ldots, N) .
\end{aligned}
$$

Let $p_{i}=\min \left(0, a_{m}, b_{n}, c_{r}\right)$; the penalty function can be described as follows:

$$
P=\frac{t+1}{2} \tau \times \sum_{i=1}^{1+m+n+r}\left(p_{i}^{2}+d_{i}^{2}\right),
$$

where $t$ is the number of iterations and $\tau$ is the penalty factor and fixed constant. Therefore, the fitness function for the real-time information-sharing model under environmental constraints is as follows: 


$$
\begin{aligned}
U= & f+P \\
= & \operatorname{Min}\left\{\sum_{n=1}^{N} g_{n} y_{n}+\sum_{m=1}^{M} \sum_{n=1}^{N} w_{m n} \operatorname{dis}_{m n} x_{m n} Y_{m n}+\sum_{n=1}^{N} \sum_{r=1}^{R} w_{n r} \operatorname{dis}_{n r} x_{n r} Z_{n r}\right. \\
+ & \sum_{n=1}^{N} h_{n}\left(\sum_{r=1}^{R} \frac{x_{n r}}{\sum_{n=1}^{N} x_{n r}} u_{r} Z_{n r}+z_{\alpha} \sqrt{\sum_{r=1}^{R} L \frac{x_{n r}}{\sum_{n=1}^{N} x_{n r}} \sigma_{r}^{2} Z_{n r}}\right) \\
& +\varepsilon\left(\sum_{n=1}^{N} c g_{n} y_{n}+\sum_{n=1}^{N} c i_{n}\left(\sum_{r=1}^{R} \frac{x_{n r}}{\sum_{n=1}^{N} x_{n r} u_{r} Z_{n r}+z_{\alpha}} \sqrt{\sum_{r=1}^{R} L \frac{x_{n r}}{\sum_{n=1}^{N} x_{n r}} \sigma_{r}^{2} Z_{n r}}\right)\right. \\
& \left.\left.\left.+\sum_{m=1}^{M} \sum_{n=1}^{N} c t_{m n} \operatorname{dis}_{m n} x_{m n} Y_{m n}+\sum_{n=1}^{N} \sum_{r=1}^{R} c t_{n r} \operatorname{dis}_{n r} x_{n r} Z_{n r}\right)-C_{\max }\right)\right\}+\frac{t+1}{2} \tau \times \sum_{i=1}^{1+m+n+r}\left(p_{i}^{2}+d_{i}^{2}\right) .
\end{aligned}
$$

4.2. The Double-Layer Bacterial Foraging Algorithm Coding for Low-Carbon E-Commerce Information-Sharing Model. Considering the information-sharing platform including multiple production nodes, multiple potential supply nodes, and multiple consumer nodes, DBFA designs a combination of discrete binary and real-valued coding. Table 1 shows the hybrid coding method.

Combined with the two-layer algorithm flow chart shown in Figures 2 and 3, the DBFA execution process showed in Figure 4 is obtained by the comprehensive design. The encoding steps of DBFA are as follows:

In Table 2, the objective function value $U$ for the particle corresponding supply node is obtained, individual extremum $p_{-}$pbest, and population extremum $g_{-}$gbest corresponding to the selected particle of supply node are calculated, the position of the bacteria is updated, and the value $U$ for the objective function in the new position is calculated.

\section{Discussion on the Case Study}

With the background of the cold chain logistics project for JD (https://fresh.jd.com), the optimal configuration of the cold chain logistics network model is solved. The three largest manufacturers in Guangzhou, Zhengzhou, and Anqing are with a maximum processing capacity of 420 tons, 360 tons, and 350 tons per unit cycle ( 2 weeks). The preliminary plan is that six refrigerated warehouses are selected in Fuzhou, Sanming, Jinhua, Hefei, Nanjing, and Nanping as potential regional suppliers to distribute to 10 retailers such as Chengdu, Xiamen, Lhasa, and Changsha. The cost of the one-year construction of the supply is apportioned to 24 cycles (24 weeks), and the construction cost is calculated periodically. Based on Ning and Chan [37], the related parameters of carbon emission in the network are set as follows: $C_{\max }=10000 \mathrm{~kg}, \varepsilon=10, \alpha=5 \%, z_{\alpha}=1.65$, and $L=1$. The data of potential suppliers are shown in Table 3 .
The relationship between the three manufacturers and the six potential suppliers is shown in Table 4, where " $a$ " denotes the manufacturer-to-supplier distance in kilometers, and " $b$ " indicates the unit transport costs from the manufacturer to the supplier for unit product, and " $c$ " indicates the unit carbon emission from the manufacturer to the supplier for unit product. Table 5 shows the data between 6 potential suppliers and 10 retailers, and the demand for 10 retailers is shown in Table 6 . The distribution of network nodes can be seen through the platform in Figure 5. Parameters $N_{c}, N_{r}$, and $N_{e}$ are shown in Table 7.

According to the data of JD.com, DBFA was used to obtain the node location and distribution plan as shown in Figure 3. Hefei and Nanping are selected as regional suppliers, in which suppliers in Hefei are directly delivered by Anqing manufacturers with the periodic distribution volume 350 tons, and suppliers in Nanping are supplied by manufacturers in Guangzhou and Zhengzhou, respectively, with 161 tons and 420 tons in Figure 6. Suppliers in Hefei are responsible for Chongqing, Changsha, Lhasa, and Wuhu, with a safety inventory 37.1 tons. Suppliers in Nanping are responsible for Kunming, Xiamen, Guiyang, Nanchang, and Chengdu, and safety inventories are 31.3 tons. Two suppliers, Hefei and Nanping, supply the retailers in Hangzhou. The hierarchy of the supply process is shown in Figure 7 and the specific freight volume of the two suppliers to each retailer is shown in Table 8 . With this site selection and distribution plan, the total cost of the real-time network is $\$ 160,1187.4$, and the carbon emission is $2,9385.7$ tons. Due to public environmental constraints, the carbon penalty cost is $\$ 19,3857.2$.

Public carbon awareness and the emission reduction policies of government have important implications to build low-carbon information-sharing network for e-companies. The location selection plan and the network operating costs are examined by changing the factors of low-carbon sustainable development and the number of initial carbon 
TABLE 1: Transportation modes.

\begin{tabular}{|c|c|c|c|c|c|c|c|}
\hline$y_{i}$ & 0 & 1 & 0 & 1 & 1 & $\ldots$ & 1 \\
\hline$W_{k i}$ & 0 & W11 W21...W91 & 0 & W13 W23...W93 & W14 W24...W94 & $\ldots$ & W19 W29...W99 \\
\hline$X_{\text {im }}$ & 0 & X10 X11..X19 & 0 & X30 X31...X39 & X40 X41...X49 & $\ldots$ & X90 X91...X99 \\
\hline
\end{tabular}

TABLE 2: The double-layer Bacterial Foraging algorithm.

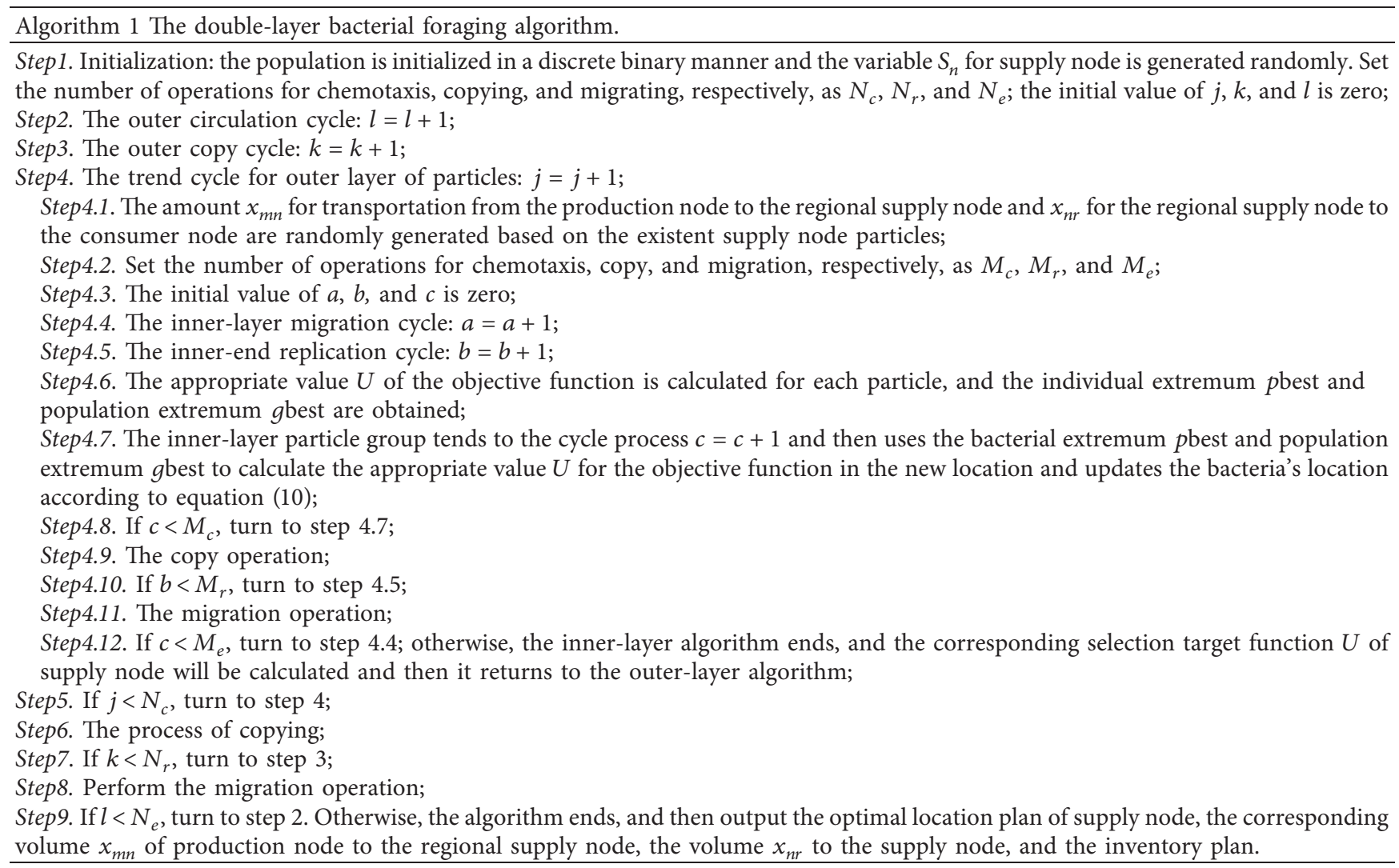

Table 3: Potential suppliers costs and carbon emissions.

\begin{tabular}{lccccc}
\hline $\begin{array}{l}\text { Potential supplier } \\
(N)\end{array}$ & $\begin{array}{c}\text { Maximum storage } \\
\text { capacity (ton) }\end{array}$ & $\begin{array}{c}\text { Construction cost } \\
(\$)\end{array}$ & $\begin{array}{c}\text { Storage cost } \\
(\$ / \text { ton })\end{array}$ & $\begin{array}{c}\text { Fixed carbon } \\
\text { emission }(\mathrm{kg})\end{array}$ & $\begin{array}{c}\text { Storage of carbon emissions } \\
(\mathrm{kg} / \text { ton })\end{array}$ \\
\hline Fuzhou $\left(n_{1}\right)$ & 585 & 77000 & 260 & 770 & 0.45 \\
Sanming $\left(n_{2}\right)$ & 590 & 79000 & 240 & 790 & 0.42 \\
Jinhua $\left(n_{3}\right)$ & 520 & 75000 & 280 & 750 & 0.48 \\
Hefei $\left(n_{4}\right)$ & 450 & 74000 & 300 & 740 & 0.50 \\
Nanjing $\left(n_{5}\right)$ & 550 & 81000 & 250 & 810 & 0.45 \\
Nanping $\left(n_{6}\right)$ & 640 & 82000 & 210 & 820 & 0.38 \\
\hline
\end{tabular}

quotas. The initial carbon quota was set at $10,000 \mathrm{~kg}$, and the low-carbon sustainable development factors were 10, 20, 30, and 40 dollars. The trend of cost is shown in Figure 8. The calculation results of the four scenarios are summarized in Table 9. Carbon quota and carbon penalty coefficients have great influence on the cost and planning design of lowcarbon supply chain.

According to Figure 8 and Table 9, the fixed carbon quota is $10,000 \mathrm{~kg}$, and the location selection plan and operational results change with the low-carbon sustainability factor. When the low-carbon sustainability factor $\varepsilon=10$, Hefei and Nanping are selected as the best location solutions, Nanjing and Nanping with $\varepsilon=20$ and $\varepsilon=30$, and Fuzhou and Hefei with $\varepsilon=40$. The overall operating costs of the network are increasing with the low-carbon sustainability factor from $\$ 1712298.5$ to $\$ 2132108$.1. However, the amount of carbon emissions in the network has shown a downward trend.

Figure 9 and Table 10 show that when $\varepsilon=20$ and the carbon quota is $30,000 \mathrm{~kg}$, the most preferred location plan is Hefei and Nanping. Because at this time, the carbon emissions are $29385.7 \mathrm{~kg}$ and less than carbon quota without carbon 
TABLE 4: Manufacturers and potential suppliers.

\begin{tabular}{lccccccccccccccccccc}
\hline & \multicolumn{1}{c}{ Fuzhou $\left(n_{1}\right)$} & \multicolumn{4}{c}{ Sanming $\left(n_{2}\right)$} & \multicolumn{3}{c}{ Jinhua $\left(n_{3}\right)$} & \multicolumn{4}{c}{ Hefei $\left(n_{4}\right)$} & \multicolumn{4}{c}{ Nanjing $\left(n_{5}\right)$} & \multicolumn{3}{c}{ Nanping $\left(n_{6}\right)$} \\
\hline & $\mathrm{a}$ & $\mathrm{b}$ & $\mathrm{c}$ & $\mathrm{a}$ & $\mathrm{b}$ & $\mathrm{c}$ & $\mathrm{a}$ & $\mathrm{b}$ & $\mathrm{c}$ & $\mathrm{a}$ & $\mathrm{b}$ & $\mathrm{c}$ & $\mathrm{a}$ & $\mathrm{b}$ & $\mathrm{c}$ & $\mathrm{a}$ & $\mathrm{b}$ & $\mathrm{c}$ \\
\hline Guangzhou $\left(m_{1}\right)$ & 228 & 3.1 & 0.1 & 68 & 3.1 & 0.07 & 308 & 3.2 & 0.08 & 582 & 3.2 & 0.08 & 596 & 3.3 & 0.07 & 20 & 3 & 0.08 \\
Zhengzhou $\left(m_{2}\right)$ & 18 & 3.0 & 0.04 & 224 & 3.1 & 0.1 & 343 & 3.2 & 0.07 & 440 & 3.3 & 0.07 & 518 & 3.2 & 0.04 & 230 & 3.1 & 0.1 \\
Anqing $\left(m_{3}\right)$ & 294 & 3.3 & 0.07 & 480 & 3.2 & 0.08 & 300 & 3.1 & 0.04 & 145 & 3 & 0.07 & 238 & 3.1 & 0.04 & 440 & 3.3 & 0.1 \\
\hline
\end{tabular}

Table 5: Potential suppliers and retailers.

\begin{tabular}{lcccccccccccccccccccc}
\hline & \multicolumn{1}{c}{ Fuzhou $\left(n_{1}\right)$} & \multicolumn{4}{c}{ Sanming $\left(n_{2}\right)$} & \multicolumn{3}{c}{ Jinhua $\left(n_{3}\right)$} & \multicolumn{4}{c}{ Hefei $\left(n_{4}\right)$} & \multicolumn{4}{c}{ Nanjing $\left(n_{5}\right)$} \\
\hline & $\mathrm{a}$ & $\mathrm{b}$ & $\mathrm{c}$ & $\mathrm{a}$ & $\mathrm{b}$ & $\mathrm{c}$ & $\mathrm{a}$ & $\mathrm{b}$ & $\mathrm{c}$ & $\mathrm{a}$ & $\mathrm{b}$ & $\mathrm{c}$ & $\mathrm{a}$ & $\mathrm{b}$ & $\mathrm{c}$ & $\mathrm{a}$ & $\mathrm{b}$ & $\mathrm{c}$ \\
\hline Chengdu $\left(r_{1}\right)$ & 357 & 3.1 & 0.1 & 166 & 3.1 & 0.1 & 370 & 3.3 & 0.08 & 663 & 3.3 & 0.1 & 667 & 3.3 & 0.07 & 128 & 3.1 & 0.1 \\
Xiamen $\left(r_{2}\right)$ & 402 & 3.1 & 0.1 & 204 & 3.1 & 0.1 & 548 & 3.4 & 0.08 & 812 & 3.4 & 0.1 & 832 & 3.4 & 0.07 & 246 & 3.1 & 0.1 \\
Lhasa $\left(r_{3}\right)$ & 708 & 3.4 & 0.07 & 850 & 3.3 & 0.07 & 506 & 3.3 & 0.04 & 280 & 3.1 & 0.07 & 172 & 3.2 & 0.04 & 772 & 3.3 & 0.07 \\
Changsha $\left(r_{4}\right)$ & 458 & 3.3 & 0.07 & 657 & 3.3 & 0.08 & 320 & 3.2 & 0.07 & 258 & 3.1 & 0.1 & 113 & 3.1 & 0.04 & 592 & 3.3 & 0.07 \\
Hangzhou $\left(r_{5}\right)$ & 450 & 3.1 & 0.04 & 496 & 3.3 & 0.07 & 148 & 3.1 & 0.04 & 324 & 3.1 & 0.07 & 243 & 3.1 & 0.04 & 445 & 3.2 & 0.07 \\
Guiyang $\left(r_{6}\right)$ & 410 & 3.1 & 0.04 & 360 & 3.3 & 0.07 & 157 & 3.2 & 0.04 & 536 & 3.3 & 0.07 & 485 & 3.2 & 0.07 & 290 & 3.2 & 0.07 \\
Nanchang $\left(r_{7}\right)$ & 90 & 3.1 & 0.04 & 317 & 3.1 & 0.1 & 372 & 3.3 & 0.07 & 375 & 3.3 & 0.04 & 484 & 3.3 & 0.07 & 324 & 3.1 & 0.1 \\
Kunming $\left(r_{8}\right)$ & 150 & 3.1 & 0.04 & 278 & 3.2 & 0.1 & 504 & 3.4 & 0.07 & 572 & 3.4 & 0.07 & 664 & 3.4 & 0.1 & 320 & 3.1 & 0.1 \\
Chongqing $\left(r_{9}\right)$ & 565 & 3.2 & 0.07 & 750 & 3.3 & 0.07 & 478 & 3.2 & 0.07 & 122 & 3.1 & 0.1 & 162 & 3.2 & 0.04 & 704 & 3.3 & 0.07 \\
Wuhu $\left(r_{10}\right)$ & 428 & 3.2 & 0.07 & 580 & 3.3 & 0.07 & 280 & 3.2 & 0.07 & 120 & 3.1 & 0.07 & 92 & 3.2 & 0.04 & 520 & 3.3 & 0.07 \\
\hline
\end{tabular}

TABLE 6: Distribution of demand for retailers.

\begin{tabular}{lcccccccccc}
\hline$(R)$ & $r_{1}$ & $r_{2}$ & $r_{3}$ & $r_{4}$ & $r_{5}$ & $r_{6}$ & $r_{7}$ & $r_{8}$ & $r_{9}$ & $r_{10}$ \\
\hline$N\left(u_{r}, \sigma_{r}\right)$ & $N(105,14)$ & $N(118,17)$ & $N(67,11)$ & $N(87,15)$ & $N(98,12)$ & $N(82,14)$ & $N(120,15)$ & $N(86,15)$ & $N(73,13)$ & $N(95,11)$ \\
\hline
\end{tabular}

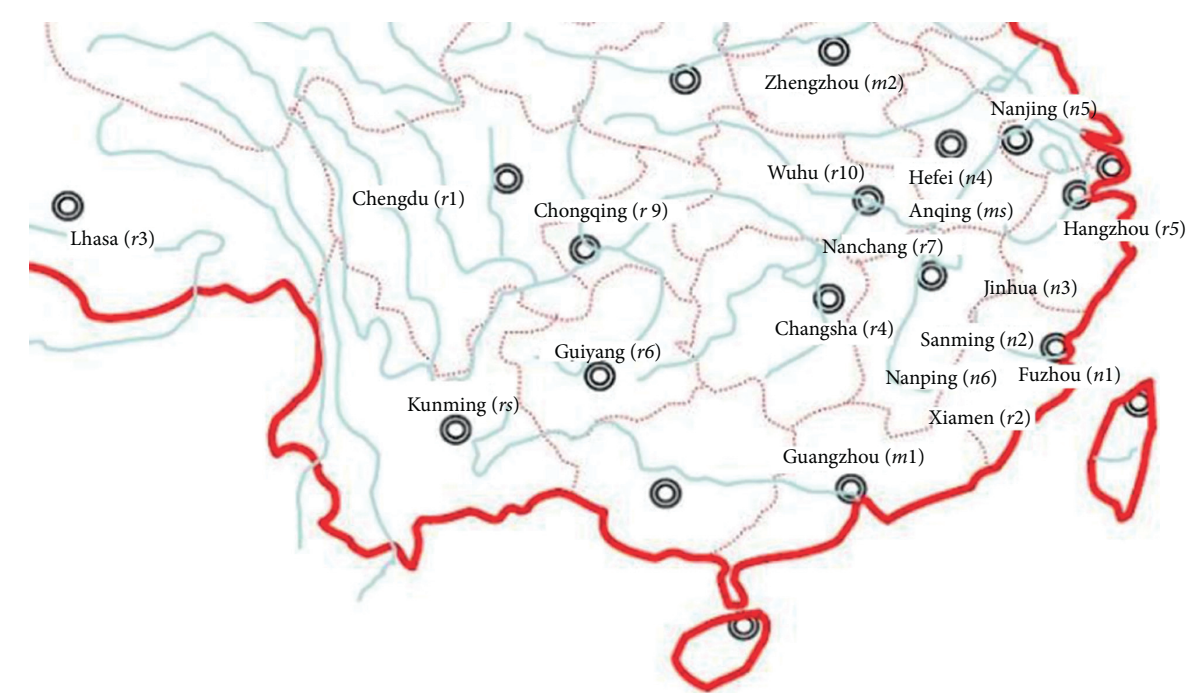

FIgURE 5: The distribution of JD cold chain logistics nodes.

TAble 7: Parameters $N_{c}, N_{r}$, and $N_{e}$.

\begin{tabular}{lcc}
\hline$N_{c}$ & $N_{r}$ & $N_{e}$ \\
\hline$[0.0,0.1,0.2,0.3,0.4,0.5,0.6,0.7,0.8,0.9,1.0]$ & {$[0.5,0.6,0.7,0.8,0.9,1.0]$} & {$[0.3,0.6,0.9]$} \\
\hline
\end{tabular}

punishment and then the cost of carbon emissions is 0 . When the carbon quota is $25000 \mathrm{~kg}$, the most optimal location plan is changed in Nanjing and Nanping, and the carbon emission is $24113.5 \mathrm{~kg}$ within carbon quota, so the carbon emission cost is 0 .
Reducing carbon emission quotas, e-companies have pressure on carbon emission, which encourages to implementing smallscale carbon emission programs, thus making real-time information-sharing network design even more low-carbon. 


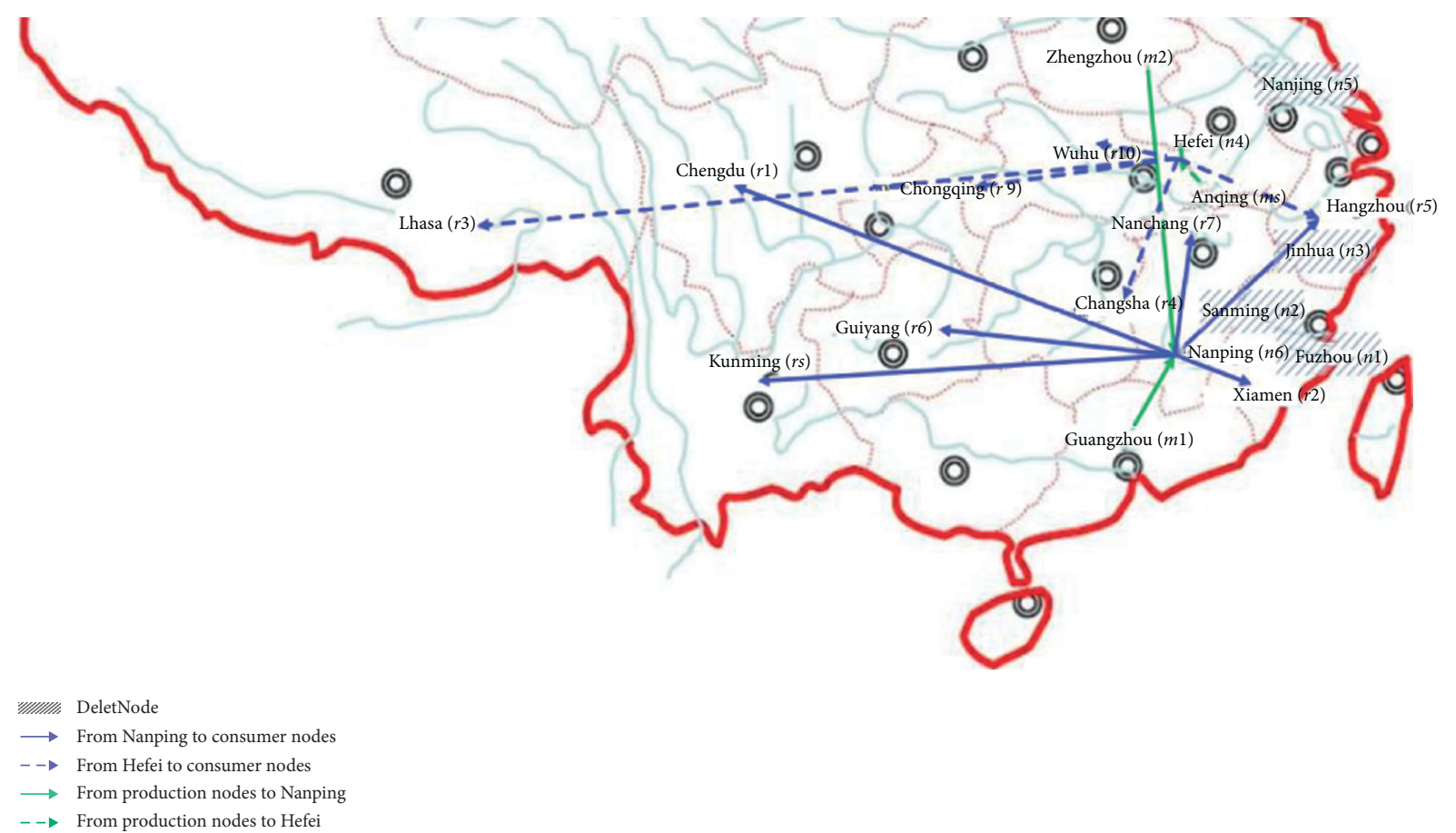

Figure 6: The cold chain logistics real-time solution.

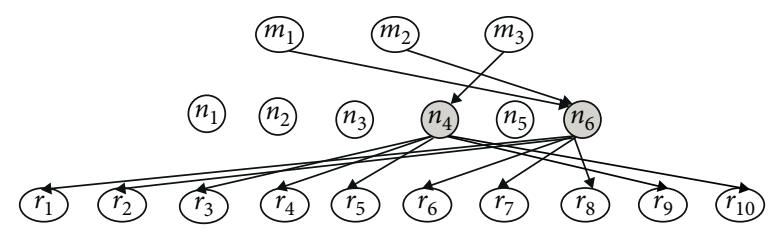

FIGURE 7: Real-time information-sharing network for JD.com.

TABLE 8: Distribution of the selected supplier to retailer.

\begin{tabular}{lcc}
\hline The selected supplier & The retailer & The quantity of output (ton) \\
\hline & $r_{1}$ & 105 \\
& $r_{2}$ & 118 \\
$n_{6}$ & $r_{7}$ & 120 \\
& $r_{8}$ & 86 \\
& $r_{6}$ & 82 \\
\hline & $r_{5}$ & 67 \\
$n_{4}$ & $r_{3}$ & 87 \\
& $r_{4}$ & 73 \\
& $r_{9}$ & 95 \\
\end{tabular}




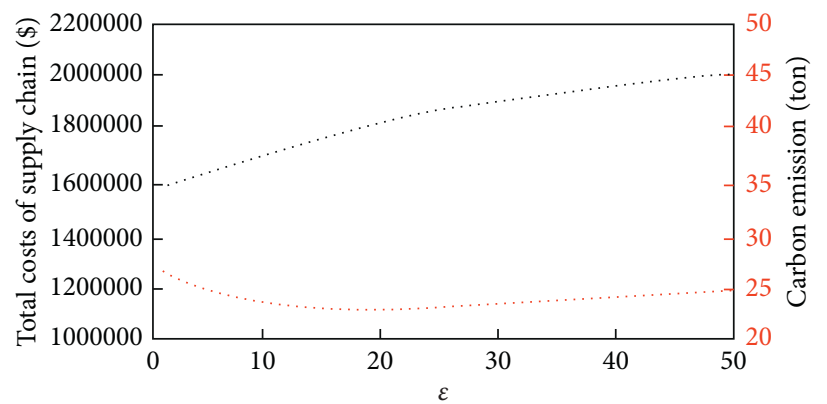

Figure 8: The impact of low-carbon sustainable development on costs and carbon emissions.

TABLE 9: Location selection plan and total cost under different low-carbon sustainable development factors.

\begin{tabular}{|c|c|c|c|c|}
\hline$\varepsilon$ & $\varepsilon=10$ & $\varepsilon=20$ & $\varepsilon=30$ & $\varepsilon=40$ \\
\hline Optimal location selection scheme & Hefei, Nanping & Nanjing, Nanping & Nanjing, Nanping & Fuzhou, Hefei \\
\hline Total costs of network $(\$)$ & 1712298.5 & 1853509.1 & 1994722.8 & 2132108.1 \\
\hline Carbon quota $(\mathrm{kg})$ & 28274.6 & 23002.4 & 25224.2 & 24351.8 \\
\hline Carbon emission $(\mathrm{kg})$ & 182746.3 & 273370.5 & 412521.7 & 531526.5 \\
\hline
\end{tabular}

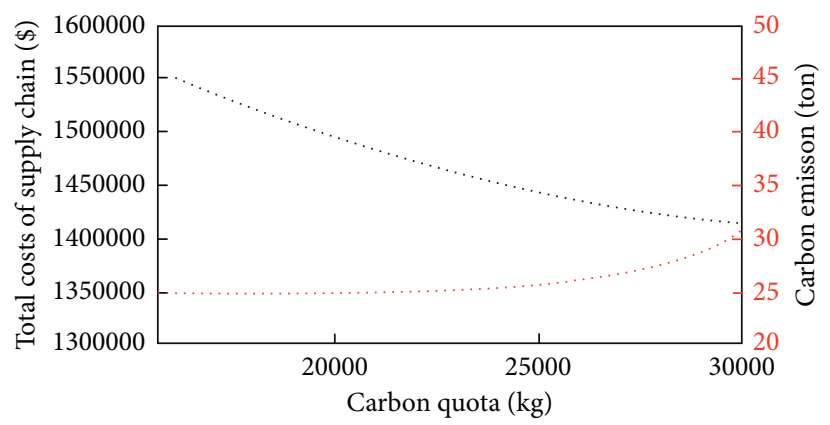

Figure 9: The impacts of carbon quota changes on costs and carbon emissions.

TABLE 10: Changes of location scheme and total cost under different carbon quota.

\begin{tabular}{lccc}
\hline Carbon quota $(\mathrm{Kg})$ & 20000 & 25000 & 30000 \\
\hline Optimal location selection scheme & Nanjing, Nanping & Nanjing, Nanping & Hefei, Nanping \\
Total costs of network (\$) & 1542498.9 & 1460229.3 & 1407330.2 \\
Carbon emission $(\mathrm{kg})$ & 24113.5 & 24113.5 & 29385.7 \\
Carbon cost $(\$)$ & 82269.6 & 0 & 0 \\
\hline
\end{tabular}

\section{Conclusions and Managerial Implications}

In this paper, the environmental protection method is studied through the model of real-time information-sharing network design.

6.1. Conclusions. The real-time information-sharing network design structure is composed of multiple production nodes, multiple supply nodes, and multiple consumer nodes. The real-time information-sharing network is established, and an double-layer DBFA is designed with internal layer and external layer, and the validity of the model and algorithm is proved. DBFA is designed and improved based on the particle swarm algorithm (PSO) in which the fast convergence rate is favorable but easily trapped in local optimum. The bacterial foraging algorithm can find the global optimal solution rapidly, but it has the characteristics of slow convergence, so the design method is divided into the inner layer and outer layer to solve the model. Among them, the inner layer of DBFA solves the supplier's transportation and inventory problems, and the outer layer algorithm solves the problem of multiple supply nodes to realize the optimization of real-time informationsharing model through nesting inside and outside layers.

\subsection{Managerial Implications and Future Research Directions.} As the carbon limit gradually decreases, the supply chain assembly will increase. With the increase of carbon penalty coefficient, the supply chain assembly will increase constantly, and the supply chain planning and design will also change with the change of carbon limit and carbon penalty coefficient. According to the change of the government's 
reduction policy of carbon emission, enterprises can timely adjust the supply chain planning and design by using the inventory model of low-carbonization multisource siting path constructed in this paper, which has good application value. When the low-carbon sustainability factor is low, most of the carbon emissions are generated while the cost of carbon emissions in the network is opposite to the lowcarbon sustainability factor.

The supplier's location and transportation volume change with the total network costs and the low-carbon sustainability factor. The government can promote the network to develop toward low-carbon environmental protection by adjusting the carbon quota and the low-carbon sustainability factor in e-commerce information-sharing model. At the same time, e-enterprises can change the government's reduction policy on carbon emission and adjust the logistics network planning according to the lowcarbon e-commerce information-sharing model to achieve the overall economic and environmental optimal goals by DBFA.

A number of extensions can be examined in future works. First, this research focuses on the carbon emissions between supply and demand, but there are also a lot of carbon emissions in the horizontal transportation between suppliers, which is a research direction in the future. Second, our model does not take into consideration the complex strategies of different operating scenarios (e.g., B2B and B2C). Future research can study this type of complex strategies and investigate what theoretical results can be derived for different types of companies. Third, this research is about real-time information but does not take into consideration the degree of real-time-like millisecond level update or hour level update, for instance.

\section{Data Availability}

The data used to support the findings of this study are included within the article.

\section{Conflicts of Interest}

The authors declare that they have no conflicts of interest.

\section{Acknowledgments}

This work was supported by Shandong Natural Science Foundation of China "Research on channel coordination strategies and consumers' behavior of $\mathrm{O} 2 \mathrm{O}$ supply chain under the background of mobile Internet" (ZR2019PG001), Scientific Research Foundation of Shandong University of Science and Technology for Recruited Talents "A multichannel supply chain model considering multiple influencing factors and consumers' heterogeneous preference" (2017RCJJ021), in part by Science-Technology Major Project of Liaoning Province, China (2019JH1/10100028), and Natural Science Foundation of China (71632008). These supports are gratefully acknowledged.

\section{References}

[1] M. D. G. Carvalho, M. Bonifacio, and P. Dechamps, "Building a low carbon society," Energy, vol. 36, no. 4, pp. 1842-1847, 2011.

[2] C. T. Lee, H. Hashim, C. S. Ho, Y. V. Fan, and J. J. Klemeš, "Sustaining the low-carbon emission development in Asia and beyond: sustainable energy, water, transportation and lowcarbon emission technology," Journal of Cleaner Production, vol. 146, pp. 1-13, 2017.

[3] L. Westman and V. C. Broto, "Climate governance through partnerships: a study of 150 urban initiatives in China," Global Environmental Change, vol. 50, pp. 212-221, 2018.

[4] A. Singla, I. P. S. Ahuja, and A. P. S. Sethi, "The effects of demand pull strategies on sustainable development in manufacturing industries," International Journal of Innovations in Engineering and Technology, vol. 8, no. 2, pp. 27-34, 2017.

[5] Y. Yu, S. Li, H. Sun et al., "Energy carbon emission reduction of China's transportation sector: an input-output approach," Economic Analysis and Policy, vol. 69, pp. 1-15, 2020.

[6] R. S. Haszeldine, "Carbon capture and storage: how green can black be?," Science, vol. 325, no. 5948, pp. 1647-1652, 2009.

[7] J. Nguyen, K. Donohue, and M. Mehrotra, "Closing a supplier's energy efficiency gap through assessment assistance and procurement commitment," Management Science, vol. 65, no. 1, pp. 122-138, 2019.

[8] J. Guo, X. Wang, S. Fan, and M. Gen, "Forward and reverse logistics network and route planning under the environment of low-carbon emissions: a case study of Shanghai fresh food E-commerce enterprises," Computers \& Industrial Engineering, vol. 106, pp. 351-360, 2017.

[9] A. O. Umoren and E. R. Enang, "IFRS adoption and value relevance of financial statements of Nigerian listed banks," International Journal of Finance \& Accounting, vol. 4, no. 1, pp. 1-7, 2015.

[10] M. Mun, S. Reddy, K. Shilton et al., "PEIR, the personal environmental impact report, as a platform for participatory sensing systems research," in Proceedings of the 7 th international conference on Mobile systems, applications, and services, pp. 55-68, Kraków Poland, June 2009.

[11] J. Gubbi, R. Buyya, S. Marusic, and M. Palaniswami, "Internet of Things (IoT): a vision, architectural elements, and future directions," Future Generation Computer Systems, vol. 29, no. 7, pp. 1645-1660, 2013.

[12] M. Falk and E. Hagsten, "E-commerce trends and impacts across Europe," International Journal of Production Economics, vol. 170, pp. 357-369, 2015.

[13] H. Pålsson, F. Pettersson, and L. Winslott Hiselius, "Energy consumption in e-commerce versus conventional trade channels - insights into packaging, the last mile, unsold products and product returns," Journal of Cleaner Production, vol. 164, pp. 765-778, 2017.

[14] Q. Sun, L. W. Jiang, and H. T. Xu, "Expectation-maximization algorithm of Gaussian mixture model for vehicle-commodity matching in logistics supply chain," Complexity, vol. 2021, Article ID 9305890, 2021.

[15] J. E. Carrillo, A. J. Vakharia, and R. Wang, "Environmental implications for online retailing," European Journal of Operational Research, vol. 239, no. 3, pp. 744-755, 2014.

[16] S. H. Chung, R. D. Weaver, and T. L. Friesz, "Strategic response to pollution taxes in supply chain networks: dynamic,spatial, and organizational dimensions," European 
Journal of Operational Research, vol. 231, no. 2, pp. 314-327, 2013.

[17] F. Caro, C. J. Corbett, T. Tan, and R. Zuidwijk, "Double counting in supply chain carbon footprinting," Manufacturing \&Service Operations Management, vol. 15, no. 4, pp. 545-558, 2013.

[18] K. M. R. Hoen, T. Tan, J. C. Fransoo, and G. J. V. Houtum, "Effect of carbon emission regulations on transport mode election under stochastic demand," Flexible Services and Manufacturing Journal, vol. 26, no. 1-2, pp. 170-196, 2014.

[19] R. Zhao, G. Neighbour, J. J. Han, M. McGuire, and P. Deutz, "Using game theory to de scribe strategy selection for environmental risk and carbon emissions reduction in the green supply chain," Journal of Loss Prevention in the Process Industries, vol. 25, no. 6, pp. 927-936, 2012.

[20] A. Diabat and D. Simchi-Levi, "A carbon-capped supply chain network problem," in Proceedings of the 2009 IEEE International Conference on Industrial Engineering and Engineering Management, pp. 523-527, Hong Kong, China, December 2009.

[21] A. Chaabane, A. Ramudhin, and M. Paquet, "Design of sustainable supply chains under the emission trading scheme," International Journal of Production Economics, vol. 135, no. 1, pp. 37-49, 2012.

[22] Y. Bouchery, A. Ghaffari, Z. Jemai, and Y. Dallery, "Including sustainability criteria into inventory models," European Journal of Operational Research, vol. 222, no. 2, pp. 229-240, 2012.

[23] S. Giarola, N. Shah, and F. Bezzo, "A comprehensive approach to the design of ethanol supply chains including carbon trading effects," Bioresource Technology, vol. 107, pp. 175-185, 2012.

[24] S. Benjaafar, Y. Li, and M. Daskin, "Carbon footprint and the management of supply chains: insights from simple models," IEEE Transactions on Automation Science and Engineering, vol. 10, no. 1, pp. 99-116, 2013.

[25] X. Gong and S. X. Zhou, "Optimal production planning with emissions trading," Operations Research, vol. 61, no. 4, pp. 908-924, 2013.

[26] S. C. Liu and S. B. Lee, "A two-phase heuristic method for the multi-depot location-routing problem taking inventory control decisions into consideration," The International Journal of Advanced Manufacturing Technology, vol. 22, pp. 941-950, 2003.

[27] X. F. Wang, "An integrated multi-depot location-inventoryrouting problem for logistics distribution system planning of a chain enterprise," in Proceedings of the 2010 International Conference on Logistics Systems and Intelligent Management, pp. 1427-1431, Harbin, China, January 2010.

[28] Z. S. Yao, L. H. Lee, W. Jaruphongsa, V. Tan, and C. F. Hui, "Multi-source facility location-allocation and inventory problem," European Journal of Operational Research, vol. 207, no. 2, pp. 750-762, 2010.

[29] E. Ballot and F. Fontane, "Reducing transportation $\mathrm{CO}_{2}$ emissions through pooling of supply networks: perspectives from a case study in French retail chains," Production Planning \& Control, vol. 21, no. 6, pp. 640-650, 2010.

[30] I. Harris, M. Naim, A. Palmer, A. Potter, and C. Mumford, "Assessing the impact of cost optimization based on infrastructure modelling on $\mathrm{CO}_{2}$ emissions," International Journal of Production Economics, vol. 131, no. 1, pp. 313-321, 2011.

[31] I. Mallidis, R. Dekker, and D. Vlachos, "The impact of greening on supply chain design and cost: a case for a developing region," Journal of Transport Geography, vol. 22, pp. 118-128, 2012.

[32] S. Pan, E. Ballot, and F. Fontane, "The reduction of greenhouse gas emissions from freight transport by pooling supply chains," International Journal of Production Economics, vol. 143, no. 1, pp. 86-94, 2013.

[33] E. Demir, T. Bektaş, and G. Laporte, "The bi-objective pollution-routing problem," European Journal of Operational Research, vol. 232, no. 3, pp. 464-478, 2014.

[34] S. Ji and Q. Sun, "Low-carbon planning and design in B \& R logistics service: a case study of an E-commerce big data platform in China," Sustainability, vol. 9, no. 11, pp. 2052-2078, 2017.

[35] K. Gao, Z. Cao, L. Zhang, Z. Chen, Y. Han, and Q. Pan, "A review on swarm intelligence and evolutionary algorithms for solving flexible job shop scheduling problems," IEEE/CAA Journal of Automatica Sinica, vol. 6, no. 4, pp. 904-916, 2019.

[36] L. Wang and J. Lu, "A memetic algorithm with competition for the capacitated green vehicle routing problem," IEEE/CAA Journal of Automatica Sinica, vol. 6, no. 2, pp. 516-526, 2019.

[37] Z. Ning and T. L. Chan, "On-road remote sensing of liquefied petroleum gas (LPG) vehicle emissions measurement and emission factors estimation," Atmospheric Environment, vol. 41, no. 39, pp. 9099-9110, 2007. 